\title{
Apply of Low-Carbon Technology in Building Energy Conservation in Hot Summer and Cold Winter Area
}

\author{
Jianlong Liu, Jinghua Yang, Hanqing Wang, Haiping Zhang and Yiyu Chen \\ College of Civil Engineering, Hunan University of Technology, Zhuzhou 412007, China
}

Received: July 28, 2013/ Accepted: September 23, 2013 / Published: February 28, 2014.

\begin{abstract}
Building energy conservation is the basis for carbon emission reduction, through elaborating the relationship between low carbon and energy efficient building. It points out that the construction of energy-saving emission reduction is an effective means to solve the problems of high energy consumption of the building, and it is also an important measure for China's carbon emission reduction. According to the climate characteristics in hot summer and cold winter area, low carbon technology suitable for the construction of energy-efficient hot summer and cold winter area is proposed which is based on the analysis of the current main building energy-saving technical measures.
\end{abstract}

Key words: Building energy conservation, low-carbon building, renewable energy.

\section{Introduction}

On December 19, 2009, “The United Nations Framework Convention on Climate Change” conference, which is held in Copenhagen, shows that although countries all over the world hold different opinions about strategies in response to climate change and the distribution of reduction of greenhouse gas emission, the subjects to reduce greenhouse gas and energy conservation are the same when facing the rigidity reality of global warming, considering the average global temperature rise of $2{ }^{\circ} \mathrm{C}$ as an acceptable "safe baseline". The Chinese government solemnly promised that, by 2020, carbon dioxide emissions decreased by $40 \%-45 \%$ per unit of GDP compared with in 2005. To reduce large-scale carbon emissions in such a short period of time, hard work and efforts are necessary, and it requires different fileds to positively participate in this task. In reducing emissions, people should be aware that the building emissions also account for a considerable role. According to statistics, the building energy consumptions (including building

Corresponding author: Jianlong Liu, Ph.D., research field: building energy saving technology. E-mail: ljlphd@sina.com. energy consumption, heating and air conditioning energy consumption, life energy consumption, etc.) account for about $30 \%$ of the total energy consumption of the whole society, of which the most important is the heating and air conditioning, and it accounts for $20 \%$. Thus, the construction of energy-efficient buildings can achieve low carbonization. That is, low-carbon technology is employed to realize energy-saving in the entire life cycle of a building [1].

\section{Building Energy Conservation and Low-Carbon Building}

Building energy conservation is mentioned as a way, by adopting the plane form and the overall layout suitable for local climate conditions in the architectural design process, to achieve the most conducive method for energy-saving, comprehensively considering a rational use and disposal of resources in the building design, construction and material selection, reducing the waste of resources, which aims at renewable resources. The low-carbon building means that it can diminish the amount of emission of carbon dioxide by reducing the use of fossil fuel and improving its 
efficiency in the process of building designing, equipment manufacturing, construction and its entire life cycle. Compared with the other green residences concept such as green real estate and other sustainable real estate, low carbon residential more emphasize on emissions of greenhouse gas-carbon dioxide caused by energy consumption.

To achieve a substantial reduction of low carbon buildings is mainly reflected in two aspects: The first one is to reduce emission of carbon by decreasing the total housing construction materials and choosing specific kind of materials, for example, the production process of wood emits less carbon dioxide than it is by steel; the other one is conservation of water, for example, running water production and waste water treatment will increase the carbon dioxide emissions, thus it is necessary for water conservation and recycling. The low carbon building has gradually become the main trend of international architecture industry, and low carbon building will also become one of the mainstream of Chinese architecture. Now China is moving in this direction. The low carbon building mainly includes two aspects: (1) low carbon materials; (2) low carbon building technology [2].

\section{Important Roles of Building Energy Conservation in Carbon Emission Reduction}

The statistics shows about $0.8 \mathrm{t}$ of carbon release from every $1 \mathrm{~m}^{2}$ of housing in China. In addition, the real estate development process involves building heating, air conditioning, ventilation, lighting and other forms of the energy, which results in a great amount of carbon emission. Therefore, to effectively control and reduce building carbon emission and establish a recycling sustainable format, it is essential to introduce more low-carbon and green building project to realize innovation in building energy-saving technology and establish a low building carbon emission system. Finally, the energy saving buildings effectively meet the corresponding standards and China's real estate industry is not only on the route one must take the healthy development, but also developers are duty-bound responsibility.

According to statistics, carbon emissions from energy consumption of the building are located only in the industry and traffic, in the third row. According to the management consulting company McKinsey analysis report, the construction field of building energy efficiency in reducing carbon emissions, is the most easy to implement but negative cost measures. In the McKinsey Co. which completed a research report about "greenhouse gas emission reduction cost curve" of a proposed carbon reduction measure, more than half of the measures are building energy-saving technology or construction belongs to negative cost measures, thus the construction of energy-saving and carbon reduction is a good measure. So, priority should be given to the development of building energy-saving in carbon reduction measures, one of the basic building energy conservation and the development of low carbon city.

\section{Low-Carbon Technology should be Applied in Energy-Saving Building in Hot Summer and Cold Winter Zone}

Building energy-saving measures in hot summer and cold winter area many of which are low carbon emissions or zero emissions, such as ground source heat pump underground heat collection, rainwater collection and utilization of photovoltaic system, solar lighting, through the light pipe will introduce indoor sunlight lighting, etc.. Then introduce the building energy-saving measures for low carbon emissions or zero carbon emissions in hot summer and cold winter zone.

\subsection{The Energy-Saving Technology in Building Enclosure Structure}

At present, China's housing unit area heating and air conditioning energy consumption is 2-3 times the consumption in developed countries which have similar climatic conditions, building envelope thermal performance is poor, and building energy conservation 
has become the first step in improving the efficiency of energy use in the whole society. Therefore, vigorously promoting the construction of energy-efficient is conducive in improving energy efficiency and energy conservation, and it is an important measure to ensure national energy security and build a low carbon economy society.

\subsubsection{Window Energy-Saving Technology}

In hot summer and cold winter zone in China, building doors and windows are an important channel to absorb solar radiation in winter, and they are also another if the main causes of indoor overheat, thus, the point is to reduce the permeability and structure of heat transfer if we struggle to meet the needs of the premise and energy-efficient doors and windows and improve the insulation performance. Reduced infiltration can be resolved mainly by setting the seal, and the volume of cold infiltrating into indoor space is determined by window pressure and thermal pressure on both sides of doors and windows. The key to controlling cold air infiltration is to set the seal and increase the air tightness, and it can help to save energy by $10 \%-15 \%$ of setting the seal. For heat transfer in enclosure structure, glasses listed below are used more popularly: hollow glass, coated glass (including reflective glass, heat absorbing glass) of high strength LOWE fireproof glass (high strength low radiation coated fire-resistant glass using magnetron sputtering method), vacuum plating metal silver layer of glass and the most special smart glass.

\subsubsection{Roof Energy-Saving Technology}

The energy-efficient constructions are achieved by intelligent technology and ecological technology, such as solar energy roof and controlled ventilation and insulation roof. Solar energy with its unique advantages is the ideal alternative energy, whose development and utilization are the ultimate solution to problems like energy shortages, environmental pollutions and greenhouse effect brought by conventional energy, especially fossil fuel. Its development and utilization will get considerable development in the 21st century, which plays an important role in the transfer of energy structure in the world mission, and becomes the dominant energy in the late 21st century.

\subsubsection{Wall Energy-Saving Technology}

External wall energy saves technology: wall with composite technology involves three types, that is, insulation layer, the insulating layer and the insulation layer. In European, most countries use the externally foamed polystyrene block. In Germany, the outer insulation building construction accounts for $80 \%$ of the total, of which $70 \%$ uses polystyrene foam board. Currently, external wall insulation method in our country has three kinds, namely, insulation, thermal insulation and exterior wall insulation sandwich, but the inner and exterior thermal insulation are used more popularly. Internal insulation is to attach wall with thermal insulation material, and the heat insulating layer is formed between the structure layer of air interlayer insulation materials to prevent damp; external insulation is to install thermal insulation material in external wall, which is covered with protective layer; and the exterior wall insulation sandwich is arranged or insulation material filled in or between the exterior masonry wall panel in.

\subsection{Building Equipment Energy-Saving}

Heating, cooling and lighting are major parts of building energy consumption, to achieve energy reduction in low carbon buildings. It is necessary to improve the energy utilization rate in demand sides (terminal), which will be considered as an alternative resource, forming virtual energy for zero-carbon emission. It changed the traditional thought which seeks to meet the increasing demand by increasing the supply of resources. In the course of long-term researches, many experts and scholars have bravely made a lot attempt to research low carbon buildings and achieved fruitful results. In the selection of construction equipment, we should use kinds of energy high efficiency. In addition, it is necessary to 
strengthen the management of the equipment operation and energy-saving monitoring.

\subsection{The Development of Low-Carbon Building Materials}

According to statistics, energy of building materials that are used in production process account for $16.7 \%$ of total social consumption, if the development of low carbon building materials will largely reduce carbon dioxide emissions. The low carbon building material sets the goal to reduce greenhouse gas emissions based on low energy consumption and low pollution, and more attention should be paid to green ecological design and recycling of usable resources. Low carbon building materials focus on reducing emission in the process of material production. In order to achieve energy conservation and emission reduction, our country should select new technology and materials to replace the materials which are highly related to high energy consumption and high emission industry (such as cement, steel and electrolytic aluminum). For example, we can frequently use timber structure markets with ecological, energy-saving market, regeneration characteristics and extensive use of low carbon mortar.

\subsection{The Use of Renewable Energy}

Buildings in hot summer and cold winter zone, based on its local climatic characteristics, can use a lot of renewable energy, such as the use of new energy technologies which are fully developed. For example, they are solar water heaters, photoelectric roof panels, wall panels, photoelectric sunshade board, photoelectric wall between windows, skylights and photoelectric glass curtain wall, etc..

4.4.1 Solar Low-Temperature Radiant Floor Heating

The low-temperature radiant floor heating refers to a way using low temperature for heating by arranging pipelines underground which take hot water below $60{ }^{\circ} \mathrm{C}$ as heating medium. It heats the floor through using the hot pipelines underground, uniformly generating heat radiation to the interior and involving characteristics like thermal stability, uniform temperature, comfort, energy saving, maintenance free, convenient management, thus it is an extremely heating ideal for rural residences. Since the heat medium temperature is low in floor radiation heating the heat source can be selected on a wide range. Using solar energy as the heat source of floor heating, is one of the optimum ways to combine solar energy utilization technology with radiant floor heating technology.

\subsubsection{Ventilation and Heat Integration}

In hot summer and cold winter in southern China, it is extremely hot in summer. It is necessary to apply ventilation in rural residences, and people need to take a shower with hot water at night. It can help strengthen the ventilation and preparation of hot water if we use solar water heater to build natural ventilation at the same time, and in this case the energy we choose is solar energy which is inexhaustible. Wei et al. [5] mentioned a scheme in which the waste heat is considered as a secondary resource in solar water heater, in which the solar energy use waste ventilation heat to improve the heating process, remove the reheating device of traditional, save energy, protect environment and achieve the purpose of energy-saving.

4.4.3 The Application of Ground Source Heat Pump

In our country, shallow geothermal resources are widely distributed and largely reserved. The expert estimates that the low-temperature contained in soil and underground water in China's shallow strata within hundreds of meters is 3,750 times of the electricity generator's installed capacity which is 400 millions KW. Moreover, low temperature available in underground water within 100 is also 200 millions KW each year. Ground source heat pump operating costs relatively low energy consumption, low maintenance cost, flexible operation, durable, and it relies on a single system, which works well in low-story building in rural areas, to heat in winter and cool in summer [4]. 


\subsubsection{Application of Wind Power in Village House}

Wind energy has such advantages as large reserves, widely distributed, no pollution, etc., and it is also an inexhaustible and renewable energy source. The use of wind power, without fuel, does not produce radiation or air pollution. Rational utilization of wind energy can both reduce the environmental pollution and ecological destruction and alleviate the pressure of energy shortage. In region which has an abundant amount of wind power, it can provide energy for the farmer's production and life through transforming wind power into electric power by mechanical devices.

\subsubsection{Building Integrated Photovoltaic}

Building integrated photovoltaic combines solar photovoltaic and building, supplying electricity by installing photovoltaic matrix on external side of the wall in building. Building integrated photovoltaic, various ways in combining matrix and building, has mainly two types: The first type is a combination of matrix and building. In this combination, photovoltaic matrix is attached to building, which works as a supporter to support the matrix; the other type of solar photovoltaic is an integration of building and photovoltaic matrix, and it comes as a kind of construction material, in which the matrix is indivisible with building. This kind of integration has been shown as photovoltaic curtain wall, photovoltaic roof, photovoltaic visor and photovoltaic lighting roof. In these two ways described above, the first combination is generally more popular and, especially, the combination of photovoltaic matrix and roof can make use of space on roof and barrier thermal radiation from the sun in summer in cold winter and hot summer regions. Science does not require extra space. This electricity supply system, which has highly attracted attention, has been widely spread and installed in cities [5].

4.4.6 Solar Building Photovoltaic/Thermoelectric System

In the practical application of building integration photovoltaic, $80 \%$ of energy from solar radiation absorbed in solar cell cannot be effectively transformed into electric energy, instead, most of solar radiation has been transformed into thermal energy, some of which help to increase the temperature of cell and weaken its efficiency in generating electricity. It can improve efficiency of generating electricity by reducing heat by endothermic media if we set channel to release the temperature. If we have ways to absorb and store these heat for electricity generating, the system can supply electricity both photoelectrically and thermoelectrically, which is so-called $\mathrm{PV} / \mathrm{TV}$ (photovoltaic/thermoelectric) system. The efficiency of the entire system equals the efficiency increased by $5 \%$ to $15 \%$ if a single solar cell works [3].

\subsection{Passive Energy-Saving Technology}

Passive energy-saving technology is a technical way to reduce energy consumption in building by employing non-mechanical and non-electric means. Specifically, it means that, while designing and planning building, we can reduce energy consumption in HVAC system through properly setting building orientation, placement of visor, thermal insulation technology in building enclosure structure and designing building outlet that is favorable for natural ventilation. Non-carbon passive energy-saving technology must be highly utilized if we reduce energy consumption in low-carbon building. For example, daylight illumination and natural ventilation are very helpful [6]. Daylight illumination diminishes the energy consumption in lighting, since there is no need to turn on the light in daytime; Natural ventilation is a significant way in building energy-saving, since it can, if is utilized properly while designing the building, realize free cooling in summer and transition seasons, improving IAQ and saving energy in air conditioning system in building. Some so-called zero-energy or zero-carbon buildings in Europe are realized by passive technology and renewable energy. We should, however, take a serious consideration on climate and 


\section{Apply of Low-Carbon Technology in Building Energy Conservation in Hot Summer and Cold Winter Area}

environment features in certain regions when applying passive technology.

\section{Conclusions}

With a drastic process of urbanization, carbon building will definitely have a high building density and plot ratio, however, one important feature of low-carbon building is that it is also energy-saving building. Energy-saving in building is a basic way to develop low-carbon building, it can better develop low-carbon and green building only if we combine tightly the low-carbon with energy-saving technology in building. In hot summer and cold winter region, the bad weather results in high energy consumption in HVAC system. It must be a significant contribution in energy-saving and emission-exhausting if we largely develop low-carbon building. Low-carbon technology mentioned in this paper works well in this climate region, and it may bring us an effective energy-saving affect if we apply it to building design process.

\section{Acknowledgements}

The work of this paper is financially supported by the National Key Technology R \& D Program of China (No. 2013BAJ10B14).

\section{References}

[1] M. Chen, Research the building energy management based on life cycle, Science \& Technology Progress and Policy 29 (18) (2012) 137-139.

[2] W. Long, W. Bai, H. Liang, Building conservation and low carbon building, Journal of Construction Economy 328 (2) (2010) 38-40.

[3] C. Wei, X. Deng, Z. Liu, Performance research on photovohaic/thermovohaic solar system in building-Itegrated solar systems, Journal of Building Science 28 (6) (2012) 36-40.

[4] M. Yang, Discussion on development trend of civilian building energy-saving technique, Journal of Architecture Technology 43 (2) (2012) 163-165.

[5] C. Wei, X. Deng, Z. Liu, Experimental study of photovoltaic/thermoelectric solar energy system based on photovoltaic thermal utilization, Journal of Renewable Energy Resources 30 (7) (2012) 5-7.

[6] J. Song, J. Yang, W. Hang, Research on the economy optimizing of passive solar building, Journal of Acta Energiae Solar Science 33 (8) (2012) 1425-1429. 